\title{
NUCLEOTIDE, RIBONUCLEOTIDE AND RIBONUCLEOSIDE BINDING BELONGS TO DIFFERENTIALLY EXPRESSED GENES IN PORCINE EPITHELIAL OVIDUCTAL CELLS DURING LONG- TERM PRIMARY CULTIVATION
}

\author{
Mariusz J. Nawrocki ${ }^{1}$, Rafał Sibiak ${ }^{2}$, Sandra Kałużna ${ }^{3}$, Maciej Brązert ${ }^{4}$, Piotr Celichowski ${ }^{3}$, Leszek
} Pawelczyk $^{4}$, Lisa Moncrieff ${ }^{5}$, Bartosz Kempisty ${ }^{1,3,6}$, Paul Mozdziak ${ }^{7}$

\begin{abstract}
The oviduct play a crucial role in reproductive process, through facilitating successful embryo growth and conception. Oviduct activity is orchestrated by various factors, depending on cyclic dynamics, which crucially affect the success of reproductive function. The morphological modifications of oviducts in response to the female reproductive cycle are well established. However, detailed characterization at the molecular level is still needed. The present study, employed primary in vitro cell cultures and high-throughput transcriptome analysis via an Affymetrix microarray approach, described nucleotide, ribonucleotide and ribonucleoside binding patterns at a molecular level in oviduct epithelial cells (OECs). 222 genes were targeted belonging to four gene ontology biological process terms (GO BP): "adenyl nucleotide binding", "adenyl ribonucleotide binding", "ribonucleotide binding", "ribonucleoside binding", which showed the greatest variability in the level of mRNA expression during of long-term cultivation. In this group of genes, special attention was paid to those showing the greatest variability in relation to the reference measurement, including OASL, PIM1, ACTA2 and ABCA1.
\end{abstract}

Running title: Oviductal nucleotide and nucleoside binding patterns

Keywords: oviductal epithelial cells, in vitro culture, nucleotide, nucleoside

\footnotetext{
${ }^{1}$ Department of Anatomy, Poznan University of Medical Sciences, Poznan, Poland

${ }^{2}$ Division of Reproduction, Department of Obstetrics, Gynecology and Gynecologic Oncology, Poznan University of Medical Sciences, Poznan,

Poland

${ }^{3}$ Department of Histology and Embryology, Poznan University of Medical Sciences, Poznan, Poland

${ }^{4}$ Department of Infertility and Reproductive Endocrinology, Poznan University of Medical Sciences, Poznan, Poland

${ }^{5}$ The School of Medicine, Medical Sciences and Nutrition, University of Aberdeen, UK

${ }^{6}$ Department of Obstetrics and Gynecology, University Hospital and Masaryk University, Brno, Czech Republic

${ }^{7}$ Physiology Graduate Program, North Carolina State University, Raleigh, North Carolina

*Correspondence: bkempisty@ump.edu.pl

Full list of author information is available at the end of article
} 


\section{Introduction}

The oviduct (uterine tube or Fallopian tube) of the domestic mammals plays a crucial role in providing an optimal microenvironment for final gamete maturation and transport, fertilization, and early embryo development [1]. Moreover, these main functions of the oviduct are highly based on its contractibility, the capacity of secreting oviductal fluid into the lumen and other oviductal components include hormones, growth factors and their receptors [2]. The characteristic feature of oviduct epithelial cells (OECs) are cilia, which facilitate the transport of the oocyte and/or the embryo. The rest of the cells in the OECs are secretory cells, that produce fluid secreted into the fallopian tube. The histological architecture of oviducts undergo substantial modification as response to reproductive cycle during lifespan of females.

Establishment and characterization of in vitro cell cultures (IVC) may be one of the most prospective methods of tissue and organ regeneration, with a large probability for application as grafts in regenerative medicine. However, despite the fact that the stem-like specificity of cells cultured primarily in vitro is well known, the cellular physiology as well as the molecular properties require further development. Long-terms primary cell cultures seem to be a very good tool for detailed characterization of different cell populations by recognition about the transcriptomic and proteomic profile and the changes that occur during cultivation.

Recent experiments indicated that the gene expression profile changes within the OECs was also accompanied by significant changes in cellular proliferation capability in vitro. The results presented in previous studies are a valuable contribution for better understanding and elucidating many biochemical pathways and morphological/metabolomic factors existing in epithelial oviductal cells. Thus, employing a microarray approach, the molecular level processes identified were angiogenesis and blood vessels development [3], carbohydrates [4] and amino acids [5] metabolism. Furthermore, and plasticity of porcine cells associated with reproduction processes $[6,7]$.

The gene expression profile in OECs primary cultured for a long-time using microarray assays is demonstrated in this study, as part of a project aimed at the molecular characterization of this cell population. Affymetrix microarray assays identified the regulatory peptides and enzymes involved in nucleotide, ribonucleotide and ribonucleoside binding pathways. In this study we demonstrated the transcripts expression variability of genes belonging to "adenyl nucleotide binding", "adenyl ribonucleotide binding", "ribonucleotide binding", "ribonucleoside binding" gene ontology biological process terms (GO BP) during OECs long-term primary culture in vitro.

\section{Material and Methods \\ Animals}

Nine month old crossbred gilts $(n=45)$ that displayed two regular estrous cycles were collected from a commercial herd. All the animals were checked daily for estrus behavior and were slaughtered after reaching the anestrus phase of the estrus cycle. The uteri were then transported to the laboratory within $30 \mathrm{~min}$ at $38^{\circ} \mathrm{C}$.

\section{Oviductal epithelial cells (OECs) selection and culture}

Oviducts were washed twice in Dulbecco's phosphate buffered saline (PBS) $(137 \mathrm{mM} \mathrm{NaCl}, 27 \mathrm{mM}$

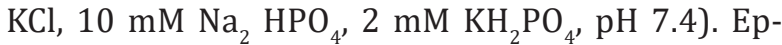
ithelial cells were surgically removed using sterile surgical blades. Then, the epithelium was incubated with collagenase I (Sigma Aldrich, Madison, USA), $1 \mathrm{mg} / \mathrm{mL}$ in Dulbecco's modified Eagle's medium (DMEM; Sigma Aldrich, Madison, USA) for $1 \mathrm{~h}$ at $37^{\circ} \mathrm{C}$. The cell suspension obtained from this digestion was filtered through $40 \mu \mathrm{m}$ pore size strainer to remove blood and single cells. The residue was collected by rinsing the strainer with DMEM. The cells were centrifuged ( $200 \mathrm{~g}, 10 \mathrm{~min})$, washed in PBS and centrifuged again. Then, the cells were incubated with $0.5 \%$ Trypsin/EDTA (Sigma Aldrich, Madison, USA) at $37^{\circ} \mathrm{C}$ for $10 \mathrm{~min}$. The reaction was stopped with fetal calf serum (FCS; Sigma Aldrich, Madison, USA). After incubation, cells where filtered and centrifuged again. The final cell pellet was suspended in DMEM supplemented with 10\% FCS, $100 \mathrm{U} / \mathrm{mL}$ penicillin, $100 \mu \mathrm{g} / \mathrm{mL}$ streptomycin and $1 \mu \mathrm{g} / \mathrm{mL}$ amphotericin B. The cells were cultured at $37^{\circ} \mathrm{C}$ in a humidified atmosphere of $5 \% \mathrm{CO}_{2}$. Once the OECs cultures attained $70-80 \%$ confluency, they were washed with PBS and passaged. The passage procedure involves cell digestion with $0.025 \%$ Trypsin/EDTA, enzyme neutralization, centrifugation of samples, and resuspension at a seeding. The culture medium was changed every three days.

\section{RNA extraction from Oviductal epithelial cells (OECs)}

Oviductal epithelial cell were pooled (10 replicates) and harvested at $24 \mathrm{~h}, 7$ days, 15 days and 30 days after the beginning of in vitro the culture. Total RNA was extracted from samples using TRI Reagent (Sigma, St Louis, MO, USA) according to the method described by Chomczyński and Sacchi [8]. The RNA was quantified by measuring the optical density (OD) at $260 \mathrm{~nm}$ (NanoDrop spectrophotometer; Thermo Scientific, Waltham, MA, USA). $100 \mathrm{ng}$ of an RNA sample was used for downstream analysis.

\section{Microarray expression analysis and statistics}

Total RNA (100 ng) from each pooled sample was subjected to two rounds of sense cDNA amplification (Ambion ${ }^{\circledR}$ WT Expression Kit, provided by 
Ambion, Austin, TX, USA). The synthesis of cRNA was performed by in vitro transcription (16 h, 40 ${ }^{\circ} \mathrm{C}$ ). Then, cRNA was purified and retranscribed into cDNA. Subsequently, cDNA samples were used for biotin labeling and fragmentation using an Affymetrix GeneChip® WT Terminal Labeling and Hybridization kit (Affymetrix). Next, the biotin-labeled samples were loaded onto and hybridized to the Affymetrix ${ }^{\circledR}$ Porcine Gene 1.1 ST Array Strip $\left(48^{\circ} \mathrm{C} / 20 \mathrm{~h}\right)$. Hybridization was conducted at $48^{\circ} \mathrm{C}$ for $20 \mathrm{~h}$, employing an AccuBlock ${ }^{\mathrm{TM}}$ Digital Dry Bath (Labnet International, Inc., Edison, NJ, USA) hybridization oven. Microarrays were washed and stained, according to technical protocol, using an Affymetrix GeneAtlas ${ }^{\mathrm{TM}}$ Fluidics Station (Affymetrix, Santa Clara, CA, USA). The strips were scanned using an Affymetrix GeneAtlas ${ }^{\mathrm{TM}}$ Imaging Station (Affymetrix, Santa Clara, CA, USA). The scans of the microarrays were saved on hard drives as *.CEL files for downstream data analysis.

All of the presented analyses and graphs were performed using Bioconductor and R programming languages. Each *.CEL file was merged with a description file. In order to correct background, normalize, and summarize results, we used the Robust Multiarray Averaging (RMA) algorithm. To determine the statistical significance of the analyzed genes, moderated t-statistics from the empirical Bayes method were performed. The obtained p-value was corrected for multiple comparisons using Benjamini and Hochberg's false discovery rate. The selection of significantly altered genes was based on a p-value beneath 0.05 and expression higher than two fold.

Differentially expressed genes were subjected selection by examination of genes involved in cell migration regulation. The differentially expressed gene list (separated for up- and down-regulated genes) was uploaded to DAVID software (Database for Annotation, Visualization and Integrated Discovery) [9], where genes belonging to the terms of all three Gene Ontology (GO) domains were extracted. Expression data of these genes were also subjected to a hierarchical clusterization procedure, and their expression values were presented as a heat map.

Subsequently the relation between the genes belonging to chosen GO terms were analyzed with GOplot package [10]. The GoPlot package had calculated the z-score: the number of up-regulated genes minus the number of down- regulated genes divided by the square root of the count. This information allowed estimating the change course of each gene-ontology term.

Interactions between differentially expressed genes/proteins belonging to the studied gene ontology group were investigated by STRING10 software (Search Tool for the Retrieval of Interacting Genes) [11]. The list of gene names was used as a query for an interaction prediction. The search criteria were based on co-occurrences of genes/proteins in sci- entific texts (text mining), co-expression, and experimentally observed interactions. The results of such analyses generated a gene/protein interaction network where the intensity of the edges reflected the strength of the interaction score.

\section{Ethical approval}

The research has been complied with all the relevant national regulations, institutional policies and in accordance the tenets of the Helsinki Declaration, and has been approved by the authors' institutional review board or equivalent committee. Poznan University of Medical Sciences Bioethics Committee approval no. 32/2012 from June 1, 2012.

\section{Results}

Whole transcriptome profiling by Affymetrix microarray allowed the analyzation of gene expression changes between 7,15 and 30 days of porcine oviductal epithelial cells culture. Through use of Affymetrix $®$ Porcine Gene 1.1 ST Array Strip, we examined expression of 12257 transcripts. Genes with fold change higher than abs (2) and wit corrected p-value lower than 0.05 were considered as differentially expressed. This set of genes consisted of 2533 different transcripts. The first detailed analysis was based on GO BP identification of differentially expressed genes belonging to the significantly enrichment GO BP terms.

DAVID (Database for Annotation, Visualization and Integrated Discovery) software was used for extraction of gene ontology biological process term (GO BP) that contains differently expressed transcripts. Up- and down-regulated gene sets were subjected to DAVID searching separately and only the gene sets which had an adj. p-value lower than 0.05 were selected. The analysis of the DAVID software showed that there were 657 differentially expressed genes belonging to the Gene ontology terms. In this paper, we focused on 222 genes that belong to "adenyl nucleotide binding", "adenyl ribonucleotide binding", "ribonucleotide binding", "ribonucleoside binding" GO BP terms. These sets of genes were subjected to the hierarchical clusterization procedure and presented as heatmaps (Fig. 1). The gene symbols, fold changes in expression, Entrez gene IDs and corrected p-values of those genes are also shown in table1.

The enrichment of each GO BP term was calculated as a z-score and shown on the circle diagram (Fig. 2).

Chosen GO BP terms contain 222 differentially expressed genes. Therefore, we calculated the mean value of mean of fold change ratio of each gene between 7, 15 and 30 days of culture. Based on that criteria we chose the 10 most down-regulated and the 10 most up-regulated genes to further analysis.

In Gene Ontology database genes that formed one particular GO group can also belong to other different GO term categories. By this reasoning, we 


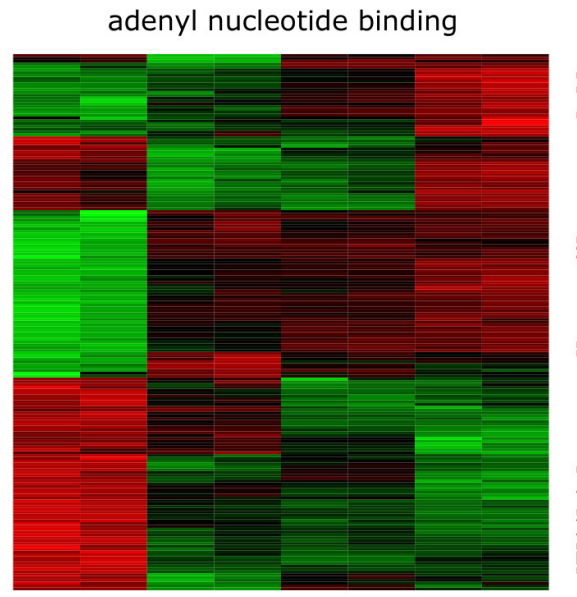

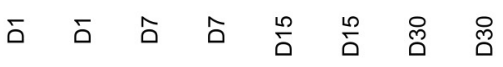

ribonucleoside binding

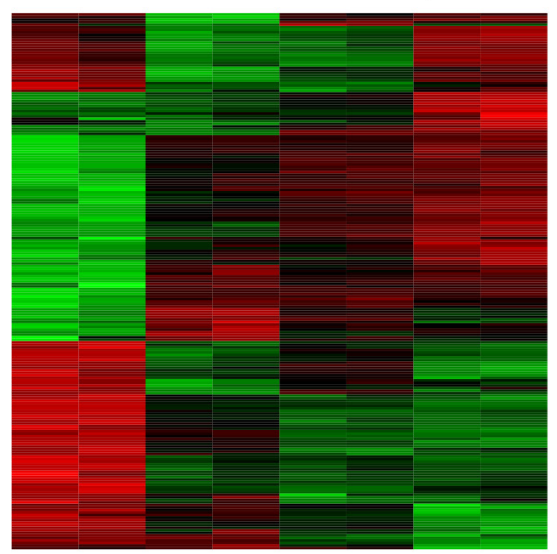

ธ ธ ธิธี adenyl ribonucleotide binding

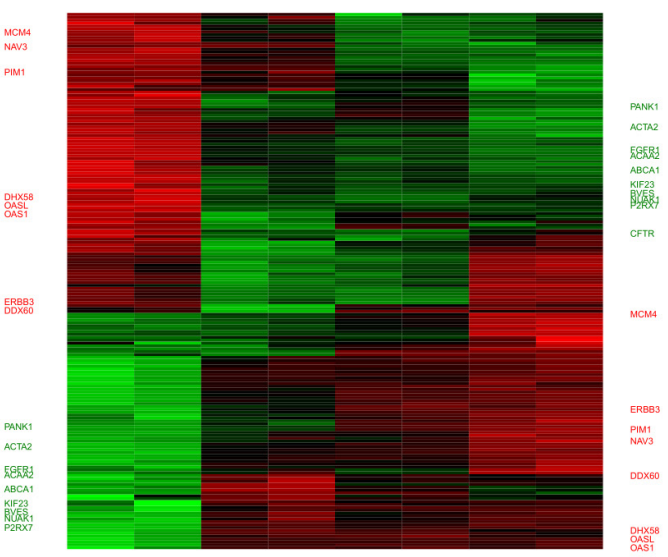

ธ

ribonucleotide binding

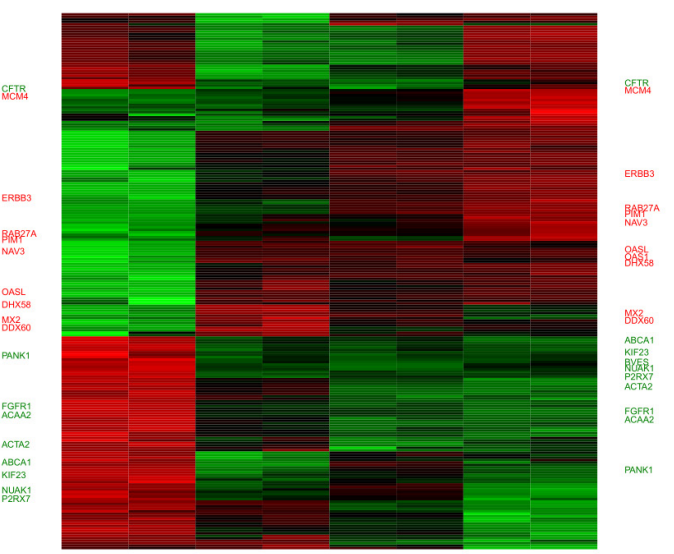

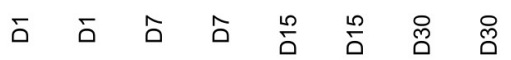

FIGURE 1. Heat map representation of differentially expressed genes belonging to the "adenyl nucleotide binding", "adenyl ribonucleotide binding", "ribonucleotide binding", "ribonucleoside binding" GO BP terms. Arbitrary signal intensity acquired from microarray analysis is represented by colours (green, higher; red, lower expression). Log2 signal intensity values for any single gene were resized to Row Z-Score scale (from -2 , the lowest expression to +2 , the highest expression for single gene). The 20 genes selected to this publication was marked green for upregulation and red for downregulation

explored the gene intersections between selected GO BP terms. The relation between those GO BP terms was presented as circle plot (Fig. 3) as well as heatmap (Fig. 4).

STRING-generated an interaction network among differentially expressed genes belonging to each of the selected GO BP terms. Using such a prediction method provided a molecular interaction network formed between protein products of studied genes (Fig. 5).

\section{Discussion}

The morphological modifications of oviducts in response to the female reproductive cycle are well established [12]. However, detailed characterization at the molecular level remains a unresolved. Establishment and depiction of primary cell cultures in vitro appears to be a good approach for comprehensive elucidating many biochemical pathways existing in ovaries. Therefore, the goal of the present project is to describe molecular changes in OECs during primary in vitro long-term culture, through employing microarray approach. Previous studies have shown various aspects of OECs' morphological modifications and transcriptomic profile changes during in vitro cultivation [3-5]. The emphasis of the present study, is on groups of genes associated with nucleotide/ribonucleotide binding mechanism.

From the whole transcript profile after the microarray assay, during long-term in vitro cell culture, the lowest transcript levels were observed for $O A S L, 2^{\prime}-5^{\prime}$-oligoadenylate synthetases (OASs) family member. OASs proteins belong to a group of IFN-induced antiviral proteins that are pivotal in the host defense mechanism against viral infection [13,14]. 2'-5'-oligoadenylate synthetase like (OASL) does not have the typical 2 '-5'-OAS activity (to catalyze the synthesis of $2^{\prime}-5^{\prime}$-oligoadenylates (2-5A) from ATP for viral RNA degradation), but have dou- 
TABLE.1 Gene symbols, fold change in expression ratio, Entrez gene IDs, corrected p values and mean value of fold change ratio of the 20 chosen differentially expressed, studied genes

\begin{tabular}{|c|c|c|c|c|c|c|c|c|}
\hline $\begin{array}{c}\text { GENE } \\
\text { SYMBOL }\end{array}$ & $\begin{array}{l}\text { RATIO } \\
\text { D7/D1 }\end{array}$ & $\begin{array}{c}\text { RATI0 } \\
\text { D15/D1 }\end{array}$ & $\begin{array}{c}\text { RATIO } \\
\text { D30/D1 }\end{array}$ & $\begin{array}{l}\text { ADJUSTED } \\
\text { P.VALUE } \\
\text { D7/D1 }\end{array}$ & $\begin{array}{l}\text { ADJUSTED } \\
\text { P.VALUE } \\
\text { D15/D1 }\end{array}$ & $\begin{array}{l}\text { ADJUSTED } \\
\text { P.VALUE } \\
\text { D30/D1 }\end{array}$ & $\begin{array}{l}\text { ENTREZ } \\
\text { GENE ID }\end{array}$ & MEAN RATIO \\
\hline OASL & -19.013577 & -19.59127971 & -20.33618335 & 2.69E-05 & 1.34E-05 & 7.93E-06 & 595119 & -19.64701335 \\
\hline PIM1 & -2.278169547 & -7.702016846 & -14.75410523 & 0.000841907 & 7.24E-06 & 1.14E-06 & 100157844 & -8.244763875 \\
\hline RAB27A & -2.438418171 & -6.421074057 & -12.17306946 & 0.000240688 & 4.70E-06 & 7.36E-07 & 606749 & -7.010853897 \\
\hline ERBB3 & -3.700854877 & -8.072357208 & -8.474685238 & $4.67 \mathrm{E}-05$ & $3.53 \mathrm{E}-06$ & $1.48 \mathrm{E}-06$ & --- & -6.749299107 \\
\hline DDX60 & -9.539122077 & -5.148779 & -4.690032007 & 7.61E-05 & 0.000244171 & 0.000232065 & --- & -6.459311028 \\
\hline NAV3 & -2.570715662 & -3.817701681 & -12.08344185 & 0.005032343 & 0.000725275 & $2.01 \mathrm{E}-05$ & --- & -6.157286398 \\
\hline MX2 & -8.476906188 & -5.025767174 & -2.864164098 & $3.11 \mathrm{E}-05$ & $6.87 \mathrm{E}-05$ & 0.000433456 & 396893 & -5.455612486 \\
\hline MCM4 & -1.824811573 & -2.553654794 & -11.20276401 & 0.001672766 & 0.000140647 & 8.81E-07 & 100156398 & -5.193743459 \\
\hline DHX58 & -6.093081701 & -5.06259312 & -3.519635478 & $2.24 \mathrm{E}-05$ & $1.83 \mathrm{E}-05$ & 4.23E-05 & 100524520 & -4.891770099 \\
\hline OAS1 & -4.734227264 & -4.803325858 & -4.579644931 & 14 & 579 & 3381 & -- & -4.705732684 \\
\hline CFTR & 5.930096417 & 5.971243553 & 3.580726141 & $4.73 \mathrm{E}-05$ & 2.79E-05 & 0.000103206 & 403154 & 5.160688703 \\
\hline BVES & 5.084835235 & 6.889451287 & 4.958469165 & 0.000164789 & 4.63E-05 & 7.99E-05 & 100153106 & 5.644251896 \\
\hline NUAK1 & 5.90004438 & 7.687798942 & 4.205418788 & 2.17E-05 & 5.48E-06 & $1.88 \mathrm{E}-05$ & 100523669 & 5.93108737 \\
\hline PANK1 & 7.855561899 & 3.491673705 & 7.158649931 & 7.45E-06 & 3.27E-05 & 2.08E-06 & 100154650 & 6.168628512 \\
\hline ACAA2 & 4.821347296 & 6.223974104 & 7.791004625 & $1.04 \mathrm{E}-05$ & $3.05 \mathrm{E}-06$ & 8.03E-07 & 100312959 & 6.278775342 \\
\hline FGFR1 & 4.599714105 & 5.650775055 & 8.942976069 & 1.33E-05 & 3.63E-06 & 6.88E-07 & 100153248 & 6.397821743 \\
\hline P2RX7 & 6.165142343 & 8.522042354 & 5.795397835 & 2.69E-05 & $6.72 \mathrm{E}-06$ & 1.03E-05 & 497623 & 6.827527511 \\
\hline KIF23 & 6.496859984 & 7.105965066 & 7.104751913 & 0.000646977 & 0.000381978 & 0.000271214 & 100522116 & 6.902525654 \\
\hline ABCA1 & 6.313396076 & 5.556746901 & 10.33557918 & 3.95E-05 & $3.12 \mathrm{E}-05$ & $4.36 \mathrm{E}-06$ & 100152112 & 7.401907384 \\
\hline ACTA2 & 5.225241405 & 12.54084054 & 30.24621828 & 3.15E-05 & 3.09E-06 & 4.37E- 07 & 733615 & 16.00410008 \\
\hline
\end{tabular}

D7/D1

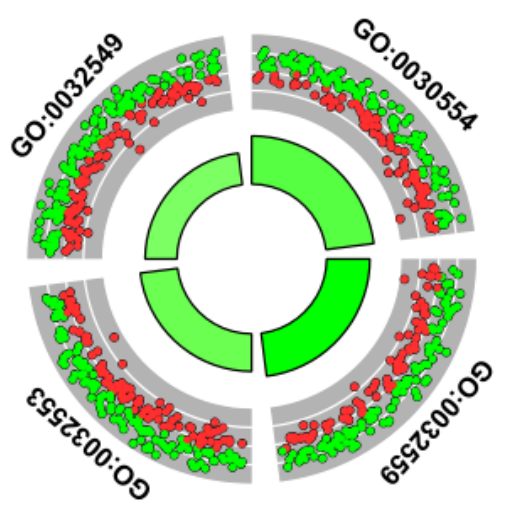

$\log \mathrm{FC}$

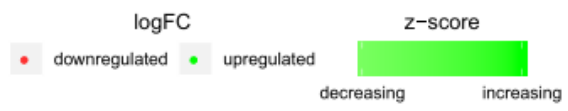

D15/D1

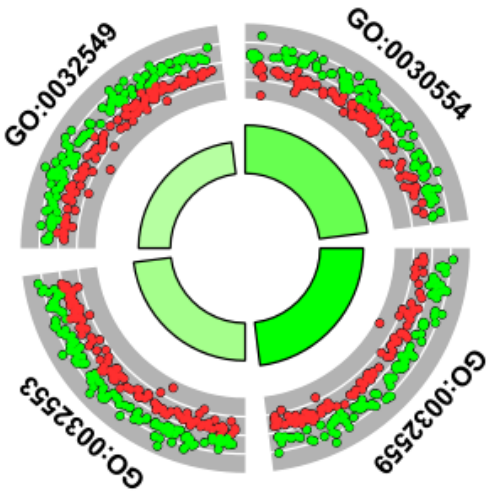

D30/D1

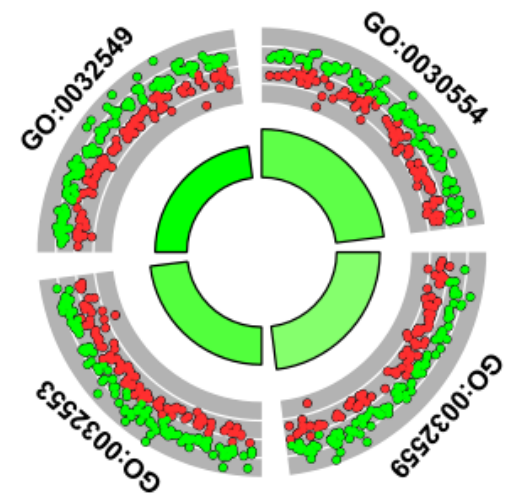

ID Description

GO:0030554 adenyl nucleotide binding GO:0032559 adenyl ribonucleotide binding GO:0032553 ribonucleotide binding GO:0032549 ribonucleoside binding

FIGURE 2. The circle plot showing the differently expressed genes and z-score of the "adenyl nucleotide binding", "adenyl ribonucleotide binding", "ribonucleotide binding", "ribonucleoside binding" GO BP terms. The outer circle shows a scatter plot for each term of the fold change of the assigned genes. Green circles display upregulation and red ones downregulation. The inner circle shows the z-score of each GO BP term. The width of the each bar corresponds to the number of genes within GO BP term and the color corresponds to the z-score 


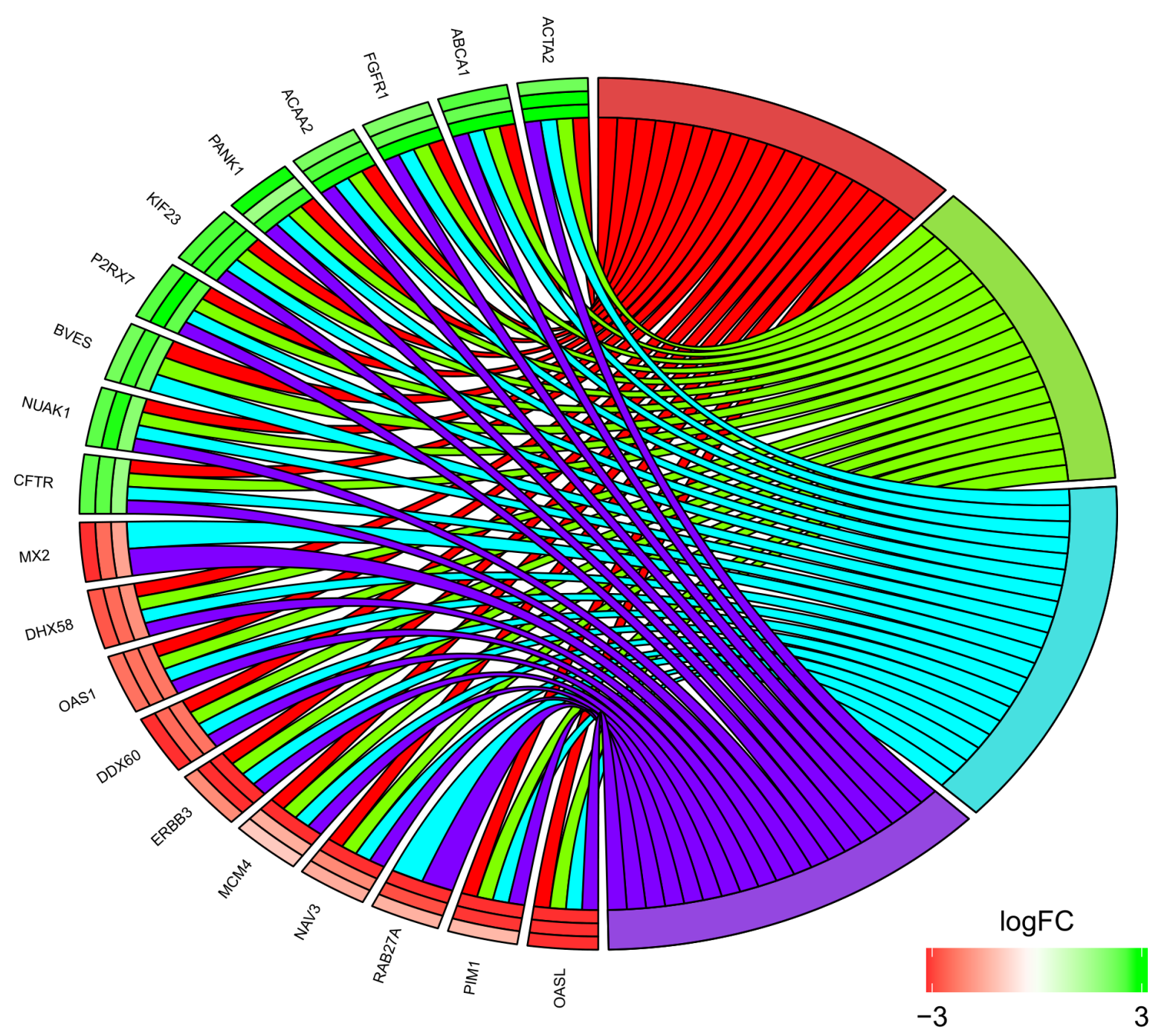

GO Terms

adenyl nucleotide binding

adenyl ribonucleotide binding

ribonucleotide binding

ribonucleoside binding

FIGURE 3. The representation of the mutual relationship of differently expressed genes that belongs to 20 chosen genes from "adenyl nucleotide binding", "adenyl ribonucleotide binding", "ribonucleotide binding", "ribonucleoside binding" GO BP terms. The ribbons indicate which gene belongs to which categories. The middle circle represents logarithm from fold change (LogFC) between D7/D1, D15/D1 and D30/D1 respectively. The color of each block corresponds to the LogFC of each gene (green - upregulated, red - downregulated). The genes were sorted by logFC from most to least changed gene

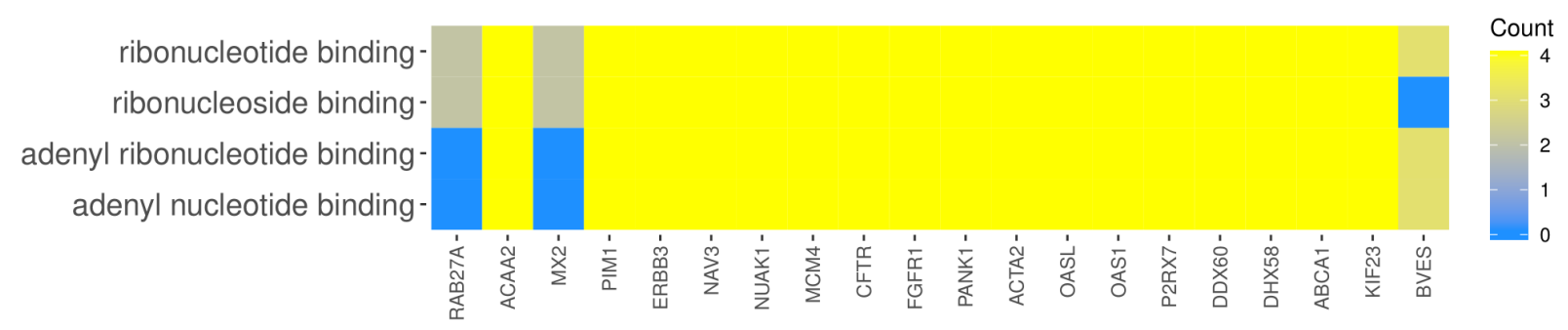

FIGURE 4. Heatmap showing the gene occurrence between chosen 20 differently expressed genes that belongs to "adenyl nucleotide binding", "adenyl ribonucleotide binding", "ribonucleotide binding", "ribonucleoside binding" GO BP terms. The yellow color is associated with gene occurrence in the GO Term. The intensity of the color is corresponding to amount of GO BP terms that each gene belongs to 


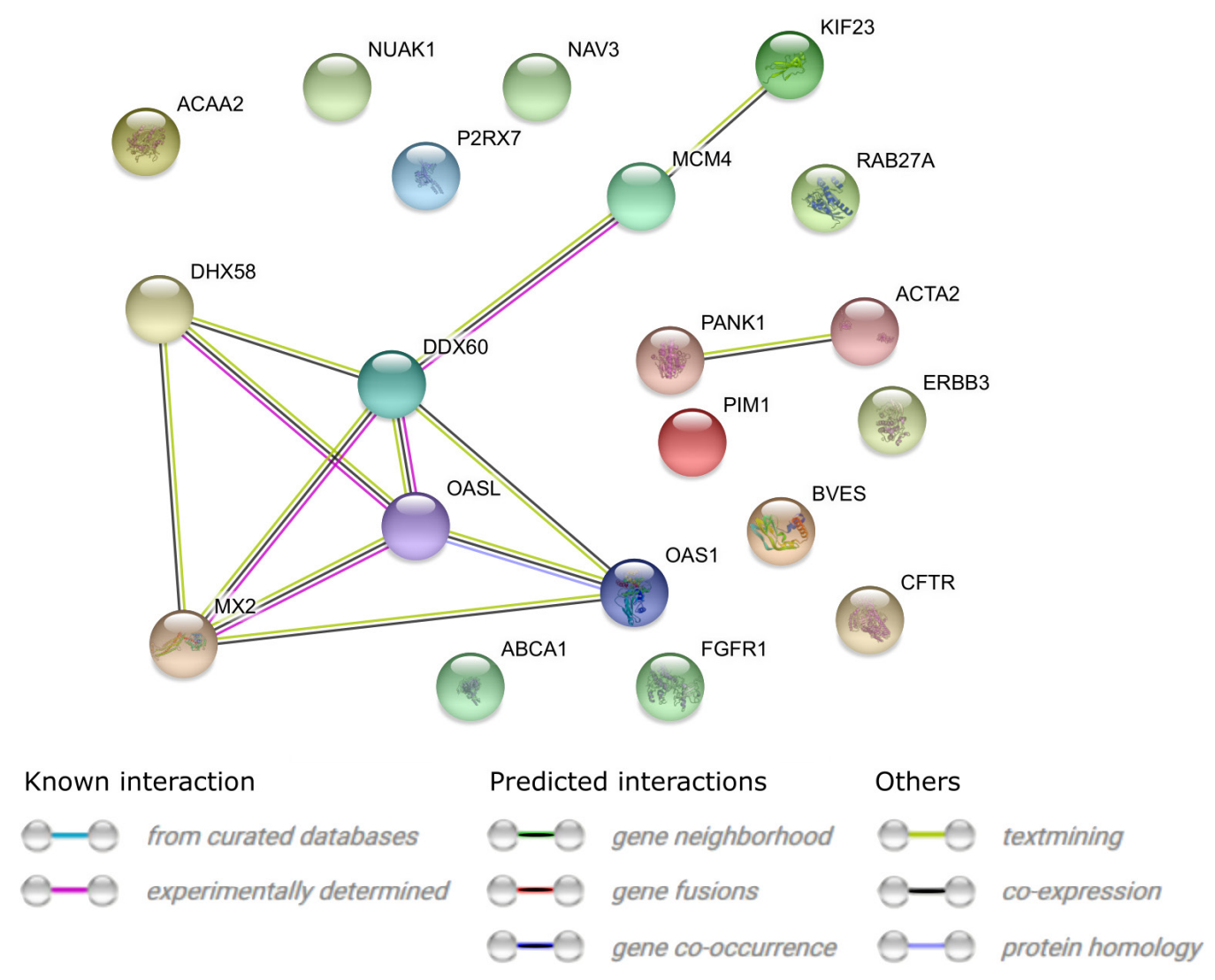

FIGURE 5. STRING-generated interaction occurrence between 20 chosen differently expressed genes that belong to the "adenyl nucleotide binding", "adenyl ribonucleotide binding", "ribonucleotide binding", "ribonucleoside binding" GO BP terms. The intensity of the edges reflects the strength of interaction score

ble-stranded RNA binding ability, and thus demonstrates antivirus activity $[15,16]$. Two homologs of human OSAL (Oasl1 and Oasl2) have been identified in mice [17]. Provided by Evsikov et al. [18], analysis of the cDNA library of Mus musculus fully grown oocytes (FGOs) reported Oasl family members transcripts are expressed. Thus, the results suggest important role of OASs family to also activate molecular pathways underlying the oocyte-to-embryo transition. Other studies by Yan et al. [19], employ targeted deletion of one of the Oasl genes, Oasl1d, which causes reduced fertility in females but not in males, demonstrating that members of this family are maternal effect genes, suggesting that OASL proteins may suppress the IFN/OAS/RNase L-mediated mRNA degradation, protecting oocyte [19]. A similar expression pattern was observed for another OASs family member, 2'-5'-oligoadenylate synthetase 1 (OAS1). Talukder et al. [20] described increased interferon-stimulated genes expression (including OAS1) in medium after co-culture of bovine oviduct epithelial cells with zygote up to embryos had reached the 16-cell stage.

The PIM family of serine/threonine kinase proteins consists of three, highly homologous, isoforms PIM1, PIM2 and PIM3. The PIM genes' expression is induced by a variety of cytokines, growth factors and mitogens [21]. The Pim1, as pro-survival kinase, has been implicated in tumorigenesis at different levels, especially in the control of cancer cells proliferation, migration and apoptosis [22]. These proteins have been labeled as "weak oncogenes" given that their overexpression induces hyperproliferation but no tumors in many cases [23]. Subsequent studies by Jiménez-García et al. [24] have described generation of two conditional PIM1 and PIM2 transgenic mice that overexpress PIM1 or PIM2 in mammary gland, uterus and ovary to characterize the proto-oncogenic role of PIM1/PIM2 in female hormone-dependent tissues. PIM1/2 overexpression induced hyperproliferation and tumors in the female reproductive system and evoked a high inflammatory response and stem markers [24]. Other research highlighted the role of Pim1 in ovarian cancer (OC) development [25]. Currently, it appears that Pim1 is overexpressed in OC and is correlated with the poor overall survival of patients. Moreover, Pim1 may significantly enhance glycolysis in OC cells. In conclusion, these results suggest that silencing or overexpressing Pim 1 can suppress or promote OC cell proliferation [25]. PIM1 transcripts expression significantly decreases over the time of cultivation. Thus decreasing activity, cell viability, because the PIM family of proteins has been 
implicated in the regulation of apoptosis, metabolism, cell cycle, homing and migration.

In comparison, the presence of numerous genes, within the analyzed ontological groups, with a different mRNA expression pattern during the culture was demonstrated. We observed a growing transcript levels for subsequent measurement points during long-term cultivation. Definitely the highest upward trend was shown by ACTA2, a gene belonging to all GO terms of interest. Expression of $\alpha$-smooth muscle actin ( $\alpha$-SMA) (encoded by the gene ACTA2) is involved in vascular contractility and blood pressure homeostasis [26]. Studies with mesenchymal stem cells (MSC) emphasized the role of Rho GTPases, Rac1 and Cdc42 in TGF $\beta$-induced $\alpha$-SMA expression in MSC [27]. A murine oviductal cell line (MOE ${ }^{\mathrm{LOW}}$ ) was also developed and then continuously passaged in culture to mimic cellular aging ( $\mathrm{MOE}^{\mathrm{HIGH}}$ ) [28]. The $\mathrm{MOE}^{\mathrm{HIGH}}$ cellular model during molecular analyses exhibited a downregulation of Acta2 transcript levels.

A member of the ATP-binding cassette (ABC) family, $A B C A 1$ also showed increased expression in cells during long-term cultivation, and was included in all discussed GO BP terms. It is well established that $\mathrm{ABC}$ family of proteins play a key role in controlling cellular and total body lipid homeostasis $[29,30]$. ABCA1 is responsible for mediating of cholesterol and phospholipids from cells to lipid-poor apolipoprotein A-I and to lipoprotein particles (e.g., high-density lipoproteins (HDL)) transport [31]. Transcriptomic analysis of the bovine oviduct epithelium exhibit lower $A B C A 1$ transcript levels in the ipsilateral side of the ampulla [32]. The promoter hypermethylation of $A B C A 1$, both in ovarian cancer cell lines and ovarian cancer patient samples, was associated with poor prognosis in ovarian cancer patients [33]. Other investigators described expression of ABC family members (including ABCA1) in mouse spermatozoa in the seminiferous tubules and epididymis [34]. Furthermore, authors have shown that ABCA1 antibody treatment of immature spermatozoa reduces cholesterol efflux to lipid acceptors and inhibits in vitro fertilization. The findings suggest that these transporters play a role the process of sterol efflux which renders spermatozoa capable of interacting and fertilizing an oocyte [34].

\section{Conclusions}

The current results characterize a large scale the transcriptomic profile of this cell population during long-term in vitro culture. The results presented in this paper indicate potential markers whose decreased expression during the cultivation may affect the reduction of activity, cell viability.

\section{Corresponding author}

Corresponding author: Bartosz Kempisty PhD, Department of Histology and Embryology, Department of Anatomy, Poznan Uni- versity of Medical Sciences, 6 Święcickiego St., 60-781 Poznań, Poland Tel./Fax: +48 618546418 / +48 618546440 , e-mail: bkempisty@ump.edu.pl.

\section{Conflict of interest statement}

The authors declare they have no conflict of interest.

\section{References}

1. Avilés M, Gutiérrez-Adán A, Coy P. Oviductal secretions: will they be key factors for the future ARTs? MHR Basic Sci Reprod Med. 2010;16:896906; D0I:10.1093/molehr/gaq056.

2. Zumoffen CM, Gil R, Caille AM, Morente C, Munuce MJ, Ghersevich SA. A protein isolated from human oviductal tissue in vitro secretion, identified as human lactoferrin, interacts with spermatozoa and oocytes and modulates gamete interaction. Hum Reprod. 2013;28:1297-308; D0I:10.1093/humrep/det016.

3. Nawrocki MJ, Celichowski P, Jankowski M, Kranc W, Bryja A, Borys-Wójcik S, Jeseta M, Antosik P, Bukowska D, Bruska M, Zabel M, Nowicki M, Kempisty B. Ontology groups representing angiogenesis and blood vessels development are highly up-regulated during porcine oviductal epithelial cells long-term real-time proliferation - a primary cell culture approach. Med J Cell Biol. 2018;6:186-94; DOI:10.2478/acb-2018-0029.

4. Nawrocki MJ, Budna J, Celichowski P, Khozmi R, Bryja A, Kranc W, Borys S, Ciesiółka S, Knap S, Jeseta M, Bukowska D, Antosik P, Brüssow KP, Bruska M, Nowicki M, Zabel M, Kempisty B. Analysis of fructose and mannose - regulatory peptides signaling pathway in porcine epithelial oviductal cells (OECs) primary cultured long-term in vitro. Adv Cell Biol. 2017;5:129-35; DOI:10.1515/acb-2017-0011.

5. Kranc W, Jankowski M, Budna J, Celichowski P, Khozmi R, Bryja A, Borys S, Dyszkiewicz-Konwińska M, Jeseta M, Magas M, Bukowska D, Antosik P, Brüssow KP, Bruska M, Nowicki M, Zabel M, Kempisty B. Amino acids metabolism and degradation is regulated during porcine oviductal epithelial cells (OECs) primary culture in vitro - a signaling pathways activation approach. Med J Cell Biol. 2018;6:18-26; DOI:10.2478/ acb-2018-0004.

6. Kranc W, Brązert M, Celichowski P, Bryja A, Nawrocki MJ, Ożegowska K, Jankowski M, Jeseta M, Pawelczyk L, Bręborowicz A, Rachoń D, Skowroński MT, Bruska M, Zabel M, Nowicki M, Kempisty B. 'Heart development and morphogenesis' is a novel pathway for human ovarian granulosa cell differentiation during long-term in vitro cultivation-a microarray approach. Mol Med Rep. 2019;19:1705-15; DOI:10.3892/ mmr.2019.9837.

7. Kulus M, Sujka-Kordowska P, Konwerska A, Celichowski P, Kranc W, Kulus J, Piotrowska-Kempisty H, Antosik P, Bukowska D, Iżycki D, Bruska M, Zabel M, Nowicki M, Kempisty B. New Molecular Markers Involved in Regulation of Ovarian Granulosa Cell Morphogenesis, Development and Differentiation during Short-Term Primary In Vitro Culture-Transcriptomic and Histochemical Study Based on Ovaries and Individual Separated Follicles. Int J Mol Sci. 2019;20:3966; DOI:10.3390/ijms20163966.

8. Chomczynski P, Sacchi N. Single-step method of RNA isolation by acid guanidinium thiocyanate-phenol-chloroform extraction. Anal Biochem. 1987;162:156-9; DOI:10.1016/0003-2697(87)90021-2.

9. Huang DW, Sherman BT, Tan Q Kir J, Liu D, Bryant D, Guo Y, Stephens R, Baseler MW, Lane HC, Lempicki RA. DAVID Bioinformatics Resources: expanded annotation database and novel algorithms to better extract biology from large gene lists. Nucleic Acids Res. 2007;35:W169-75; DOI:10.1093/nar/gkm415.

10. Walter W, Sánchez-Cabo F, Ricote M. GOplot: an R package for visually combining expression data with functional analysis: Fig. 1. Bioinformatics. 2015;31:2912-4; DOI:10.1093/bioinformatics/btv300.

11. von Mering C, Jensen LJ, Snel B, Hooper SD, Krupp M, Foglierini M, Jouffre N, Huynen MA, Bork P. STRING: known and predicted protein-protein associations, integrated and transferred across organisms. Nucleic Acids Res. 2005;33:D433-7; DOI:10.1093/nar/gki005.

12. Besenfelder U, Havlicek V, Brem G. Role of the Oviduct in Early Embryo Development. Reprod Domest Anim. 2012;47:156-63; DOI:10.1111/j.1439-0531.2012.02070.x.

13. Player MR, Torrence PF. The 2-5A system: modulation of viral and cellular processes through acceleration of RNA degradation. Pharmacol Ther. 1998;78:55-113; DOI:10.1016/s0163-7258(97)00167-8.

14. Kakuta S, Shibata S, Iwakura Y. Genomic Structure of the Mouse 2',5'-Oligoadenylate Synthetase Gene Family. J Interf Cytokine Res. 2002;22:981-93; DOI:10.1089/10799900260286696.

15. Hartmann R, Olsen HS, Widder S, Jørgensen R, Justesen J. p590ASL, a 2'-5' oligoadenylate synthetase like protein: A novel human gene related to the 2' -5 ' oligoadenylate synthetase family. Nucleic Acids Res. 1998;26:4121-7; DOI:10.1093/nar/26.18.4121. 
16. Ishibashi M, Wakita T, Esumi M. 2',5'-Oligoadenylate synthetase-like gene highly induced by hepatitis $\mathrm{C}$ virus infection in human liver is inhibitory to viral replication in vitro. Biochem Biophys Res Commun. 2010;392:397-402; DOI:10.1016/j.bbrc.2010.01.034

17. Shibata S, Kakuta S, Hamada K, Sokawa Y, Iwakura Y. Cloning of a novel 2',5'-oligoadenylate synthetase-like molecule, Oasl5 in mice. Gene. 2001;271:261-71; DOI:10.1016/s0378-1119(01)00508-x.

18. Evsikov A V, Graber JH, Brockman JM, Hampl A, Holbrook AE, Singh P, Eppig JJ, Solter D, Knowles BB. Cracking the egg: molecular dynamics and evolutionary aspects of the transition from the fully grown oocyte to embryo. Genes Dev. 2006;20:2713-27; DOI:10.1101/gad.1471006.

19. Yan W, Ma L, Stein P, Pangas SA, Burns KH, Bai Y, Schultz RM, Matzuk MM. Mice Deficient in Oocyte-Specific Oligoadenylate Synthetase-Like Protein OAS1D Display Reduced Fertility. Mol Cell Biol. 2005;25:4615-24 DOI:10.1128/MCB.25.11.4615-4624.2005

20. Talukder AK, Rashid MB, Yousef MS, Kusama K, Shimizu T, Shimada M, Suarez SS, Imakawa K, Miyamoto A. Oviduct epithelium induces interferon-tau in bovine Day-4 embryos, which generates an anti-inflammatory response in immune cells. Sci Rep. 2018;8:7850; DOI:10.1038/ s41598-018-26224-8.

21. Warfel NA, Kraft AS. PIM kinase (and Akt) biology and signaling in tumors. Pharmacol Ther. 2015;151:41-9; DOI:10.1016/j. pharmthera.2015.03.001.

22. Magnuson NS, Wang Z, Ding G, Reeves R. Why target PIM1 for cancer diagnosis and treatment? Future Oncol. 2010;6:1461-78; DOI:10.2217/ fon.10.106.

23. Xu J, Zhang T, Wang T, You L, Zhao Y. PIM kinases: an overview in tumors and recent advances in pancreatic cancer. Future Oncol. 2014;10:86576; DOI:10.2217/fon.13.229.

24. Jiménez-García MP, Lucena-Cacace A, Robles-Frías MJ, Ferrer I, Narlik-Grassow M, Blanco-Aparicio C, Carnero A. Inflammation and stem markers association to PIM1/PIM2 kinase-induced tumors in breast and uterus. Oncotarget. 2017;8:58872-86; DOI:10.18632/oncotarget.19438.

25. Wu Y, Deng Y, Zhu J, Duan Y, Weng WW, Wu X. Pim1 promotes cell proliferation and regulates glycolysis via interaction with MYC in ovarian cancer. Onco Targets Ther. 2018;11:6647-56; DOI:10.2147/OTT.S180520.

26. Hinz B. Myofibroblasts. Exp Eye Res. 2015;142:56-70; DOI:10.1016/j exer.2015.07.009.

27. Ge J, Burnier L, Adamopoulou M, Kwa MQ, Schaks M, Rottner K, Brakebusch C. RhoA, Rac1, and Cdc42 differentially regulate SMA and collagen i expression in mesenchymal stem cells. J Biol Chem. 2018;293:935869; DOI:10.1074/jbc.RA117.001113.

28. Endsley MP, Moyle-Heyrman G, Karthikeyan S, Lantvit DD, Davis DA, Wei JJ, Burdette JE. Spontaneous transformation of murine oviductal epithelial cells: A model system to investigate the onset of fallopian-derived tumors. Front Oncol. 2015;5; DOI:10.3389/fonc.2015.00154.

29. Rust S, Rosier M, Funke H, Real J, Amoura Z, Piette JC, Deleuze JF, Brewer HB, Duverger N, Denèfle P, Assmann G. Tangier disease is caused by mutations in the gene encoding ATP-binding cassette transporter 1 . Nat Genet. 1999;22:352-5; DOI:10.1038/11921.

30. Fielding PE, Nagao K, Hakamata H, Chimini G, Fielding CJ. A two-step mechanism for free cholesterol and phospholipid efflux from human vascular cells to apolipoprotein A-1. Biochemistry. 2000;39:14113-20, DOI:10.1021/bi0004192.

31. Vaughan AM, Oram JF. ABCA1 and ABCG1 or ABCG4 act sequentially to remove cellular cholesterol and generate cholesterol-rich HDL. J Lipid Res. 2006;47:2433-43; DOI:10.1194/jlr.M600218-JLR200.

32. Locatelli Y, Forde N, Blum H, Graf A, Piégu B, Mermillod P, Wolf E, Lonergan $P$, Saint-Dizier M. Relative effects of location relative to the corpus luteum and lactation on the transcriptome of the bovine oviduct epithelium. BMC Genomics. 2019;20; DOI:10.1186/s12864-019-5616-2.

33. Chou J-L, Huang R-L, Shay J, Chen L-Y, Lin S-J, Yan PS, Chao W-T, Lai Y-H, Lai Y-L, Chao T-K, Lee C-I, Tai C-K, Wu S-F, Nephew KP, Huang TH-M, Lai $\mathrm{H}-\mathrm{C}$, Chan MWY. Hypermethylation of the TGF- $\beta$ target, ABCA1 is associated with poor prognosis in ovarian cancer patients. Clin Epigenetics. 2015;7:1; DOI:10.1186/s13148-014-0036-2.

34. Morales CR, Marat AL, Ni X, Yu Y, Oko R, Smith BT, Argraves WS. ATP-binding cassette transporters ABCA1, ABCA7, and ABCG1 in mouse spermatozoa. Biochem Biophys Res Commun. 2008;376:472-7; DOI:10.1016/j.bbrc.2008.09.009. 